\title{
Avaliação do efeito da suplementação terapêutica com probiótico em cães filhotes com gastrenterite hemorrágica
}

\section{Evaluation of the therapeutic supplementation with commercial powder probiótic to puppies with hemorrhagic gastroenteritis}

\author{
Pedro Luiz de Camargo ${ }^{1 *}$; Maria Beatriz Tassinari Ortolani ${ }^{2}$; Simone Akemi \\ Uenaka $^{2}$; Maitê Bette Motta ${ }^{2}$; Cecília dos Reis Braga ${ }^{3}$; Pâmela Cristina dos Santos ${ }^{3}$; \\ Jamil Correia da Silva Júnior ${ }^{4}$; Viviane Gonçalves Vieira ${ }^{4}$; Alice Fernandes Alfieri ${ }^{5}$
}

\section{Resumo}

\begin{abstract}
A gastrenterite hemorrágica (GHE) é uma afecção comum em filhotes de cães, e motivo freqüente de internação e mortalidade. Considerando que probióticos têm sido apontados como benéficos no tratamento destes pacientes, avaliamos o impacto da inclusão de probiótico à base de Lactobacilus acidophillus em 100 filhotes de cães com GHE, distribuídos em dois grupos de 50 indivíduos. Os cães do grupo 1 (G1), além da terapia indicada para GEH, constituída de fluido e antibiótico terapia e antiemético, receberam, por via oral, probiótico. Para os animais do grupo 2 (G2) foi adotada apenas a terapêutica convencional. Foram quantificadas as partículas virais nas fezes, pela hemaglutinação (HA) e os anticorpos (Ac) anti-parvovírus por inibição da hemaglutinação. Foram registradas a duração da internação e a tolerância dos animais ao probiótico. A excreção viral nas fezes pelos animais de ambos os grupos foi semelhante no momento da internação $(\mathrm{P}=0,746)$ e da alta hospitalar $(\mathrm{P}=0,294)$. Entretanto, no $\mathrm{G} 1$ a excreção foi significativamente menor no momento da alta $(\mathrm{p}<0,001)$. O período de internamento variou de um a 15 dias no $\mathrm{G} 1$ e de um a 10 dias no $\mathrm{G} 2(\mathrm{P}=0,70)$. A taxa de mortalidade no $\mathrm{G} 1$ foi de $37,50 \%$ (18/ $48)$ e de $26 \%$ (13/50) no $\mathrm{G} 2(\mathrm{P}=0,49)$. A aceitação do probiótico variou de regular a ótima em $95 \%$ das administrações, porém, os animais que foram a óbito demonstraram intolerância. Com estas observações não foi estabelecida relação entre a administração de probiótico e recuperação da doença, abreviação do período de internação ou ao aumento da resposta humoral. Porém, a suplementação reduziu a excreção fecal de vírus, o que é benéfico quando se considera a menor disseminação do vírus no ambiente.

Palavras-chave: Cão, probiótico, gastrenterite hemorrágica, parvovirose.
\end{abstract}

Professor adjunto doutor do Departamento de Clínicas Veterinárias; CCA; UEL. E-mail: p.camargo@uel.br.

Aluna do Curso de Graduação em Medicina Veterinária e estagiária do Programa de Iniciação-Científica - PROIC da UEL.

Aluno do Curso de Graduação em Medicina Veterinária da UEL.

4 Pós-graduando - Programa de Residência em Clínica Médica, Cirúrgica e Reprodução de Animais de Companhia; DCV; CCA; UEL.

5 Professora Adjunta Doutora; Departamento de Medicina Veterinária Preventiva; CCA; UEL.

* Autor para correspondência 


\begin{abstract}
Hemorrhagic gastroenteritis (GHE) is a common motivation to hospitalization and mortality between puppies. Considering the beneficial effects of probiotics in the treatment of some gastrointestinal disorders, we evaluated the usefulness of the probiotic product in 100 puppies hospitalized because GHE. Fifth dogs were treated by intravenous fluid, antiemetic, antibiotics and probiotic product (G1), and the other 50 only by supportive and symptomatic therapy (G2). We accessed the titters of anticorpus anti-parvovirus by $\mathrm{HI}$, fecal excretion of virus by HA and registered the duration of internation period and tolerance to probiotic ingestion. The titters of $\mathrm{HI}$ were similar between $\mathrm{G} 1$ and $\mathrm{G} 2$ in the samples from entrance $(\mathrm{P}=$ $0,553)$ and at the hospital discharge $(\mathrm{P}=0,844)$, moreover arises during hospitalization in booth groups $(\mathrm{P}<0,001)$. The fecal excretion of virus of $\mathrm{G} 1$ and $\mathrm{G} 2$ were similar in booth moments $(\mathrm{P}=0,746$ and $\mathrm{P}=$ 0,294 , respectively) furthermore the G1 showed lowest fecal titters of virus at hospital discharge $(\mathrm{P}<$ 0,001). The internation period in the G1 variates one to 15 days and one to 10 days in the G2 group, without statistical difference between the groups $(\mathrm{P}=0,70)$. The rate of mortality in the $\mathrm{G} 1$ was $37,50 \%$ $(18 / 48)$ and $26 \%(13 / 50)$ in the $\mathrm{G} 2$, lacking statistical significance $(\mathrm{P}=0,49)$. Probiotic tolerance was regular to excellent in $95 \%$ of the administrations, furthermore the animals that died demonstrate intolerance. These observation permits no established a relationship between the administration of Lactobacilus acidophillus based probiotic and shortening treatment duration, improved in the disease evolution or anticorpus production, likewise showed positive influence over fecal excretion of virus. Considering the parvovirosis, this is a desirable factor to decrease dissemination of the disease between susceptible population.
\end{abstract}

Key words: Dog, probiotic, hemorragic gastrrenteritis, parvovirosis.

\section{Introdução}

Nas espécies monogástricas, como o cão, a microbiota residente do estômago e intestino delgado proximal é composta principalmente por estreptococos, estafilococos e lactobacilos. Ainda no intestino delgado podem ser vistas pequenas quantidades de coliformes e, intermitentemente, microrganismos anaeróbios ou gram negativos (BURROWS; BATT; SHERDING, 1995). Esta microbiota desempenha diversas funções metabólicas e de defesa contra infecções bacterianas importantes para o organismo hospedeiro (LIDBECK; NORD, 1993).

Os benefícios da associação do hospedeiro com bactérias produtoras de ácido láctico têm sido sugeridos há mais de cem anos e, em tempos mais recentes, diversos estudos têm sido realizados com o objetivo de confirmar estes benefícios. Em relação ao trato gastrintestinal, sabe-se que o epitélio sadio associado a uma microbiota intestinal residente compõe uma barreira contra invasão ou colonização por microrganismos patogênicos, antígenos, ou compostos danosos presentes na luz intestinal (HOLZAPFEL; SCHILLINGER, 2002).
Produtos probióticos têm sido sugeridos como facilitadores dos processos digestivos e imunológicos, visto que auxiliariam na instalação, reconstituição ou estabilização da microbiota intestinal em animais de qualquer idade. Este potencial benéfico tem sido estendido mesmo ao estômago, sendo sugerido que probióticos poderiam ser úteis na erradicação do Helicobacter pylori em pessoas (CANDUCCI et al., 2002).

Em pessoas sadias verificou-se que, mesmo com capacidade de colonizar o intestino, determinadas cepas de lactobacilos não foram capazes de induzir reposta inflamatória ou imunomediada (GARDINER et al., 2002). Por outro lado, a administração de probiótico à base de Lactobacillus paracasei induziu aumento significativo no número de células que expressam CD4 e do índice de fagocitose, indicando que esta suplementação teria atuação imunomoduladora (JAHREIS et al., 2002).

Da mesma forma, o uso de probióticos no tratamento de pessoas com diarréia aguda de origem infecciosa, notadamente aquelas causadas pelo rotavirus, tem se mostrado promissor. Estudos neste 
sentido propõem que a administração de probióticos encurta o tempo de curso da doença e o período de excreção fecal de vírus (ISOLAURI et al., 1994; GUARINO et al., 1997; SHORNIKOVA et al., 1997; SIMAKACHORN et al., 2000; LEE et al., 2001; ROSENFELDT et al., 2002a; ROSENFELDT et al., 2002b). Estas conclusões foram corroboradas por estudos meta-analíticos (SZAJEWSKA; MRUKOWICZ, 2001; VAN NIEL et al., 2002).

Existem também indícios de que probióticos restabelecem o transporte aberrante de macromoléculas através da mucosa intestinal, sugerindo sua aplicabilidade na reversão do aumento de permeabilidade induzida por inflamação intestinal (PESSI et al., 1998).

$\mathrm{Na}$ espécie canina, os problemas ligados à dieta assim como às infecções virais ou parasitárias têm sido apontados como as principais causas de diarréias agudas. No caso da gastrenterite hemorrágica (GHE), uma condição clínica comum em nosso meio, a destruição epitelial favorece a penetração de bactérias intestinais e absorção de toxinas. A antibiótico terapia rotineiramente implementada neste tipo de quadro clínico pode interferir negativamente na manutenção da barreira de defesa intestinal contra infecções (LIDBECK; NORD, 1993).

No caso específico da GHE induzida pelo parvovírus canino, a sepse, notadamente por enterobactérias gram negativas, como a Salmonella sp. e E. coli, é um importante fator de risco de mortalidade (HAGIWARA; MAMIZUKA; PAVAN, 1996).

Considerando-se que probióticos desempenhem papel positivo como imunomoduladores e no restabelecimento da permeabilidade da mucosa, a somatória destes fatores sugere que a introdução de probióticos no protocolo de tratamento de animais com GEH possa favorecer o paciente. Por conta disso, este estudo teve como objetivos verificar a tolerância de filhotes de cães com GEH à administração oral de produto probiótico e a validade da inclusão deste suplemento no tratamento através da verificação da manifestação de efeitos benéficos decorrentes da suplementação. No caso de filhotes com GEH causadas pelo parvovírus canino, verificar se este tratamento interfere na duração do tempo de internação, na duração ou quantidade de partículas virais eliminadas, assim como na produção de anticorpos, durante o período de internação.

\section{Material e Métodos}

\section{Animais}

Foram incluídos neste estudo 100 cães com idade variando de dois a oito meses, fêmeas ou machos, de diferentes raças ou sem raça definida, atendidos no Setor de Pronto Atendimento (Plantão) do Hospital Veterinário da Universidade Estadual de Londrina, por apresentarem anorexia, depressão, vômito e/ou diarréia com sangue e para os quais, devido a gravidade de seu quadro clínico, havia indicação de tratamento sob internação.

Estes animais foram distribuídos aleatoriamente no Grupo 1 (G1) e Grupo 2 (G2), sendo o G1 composto pelo primeiro animal incluso na pesquisa, pelo terceiro, quinto, e assim sucessivamente, e o G2, pelo segundo animal, quarto, sexto, sucessivamente até completar 50 cães em cada grupo. O G1 foi designado como grupo de tratamento e o G2 como grupo controle.

\section{Tratamento e acompanhamento dos animais}

No momento da internação os animais do G1 e G2 passaram por exame físico completo para avaliação da condição clínica e receberam tratamento protocolar para GEH que consistia de solução multieletrolítica (Ringer com lactato), suplementada com cloreto de potássio a 10\% (5 mL em $500 \mathrm{~mL}$ de Ringer com lactato), administrada IV, em volume suficiente para satisfazer às necessidades estimadas do paciente. Além disso, era administrado metoclopramida (0,5 mg/kg, IV, TID); cimetidina (10 $\mathrm{mg} / \mathrm{kg}, \mathrm{SC}, \mathrm{TID})$, e cefalexina (35 mg/kg, IV, BID). 
Os animais do G1 receberam adicionalmente produto probiótico (Enterolac ${ }^{\circledR}$ - Agener União Saúde Animal - São Paulo, SP.) administrado pela via oral seguindo a recomendação do fabricante. O conteúdo de um sache era diluído em $5 \mathrm{~mL}$ de água e administrados $2,5 \mathrm{~mL}$ para os animais com até $5 \mathrm{~kg}$ de peso corpóreo, $5 \mathrm{~mL}$ para animais com peso entre 5 e $10 \mathrm{~kg}$, e 10 $\mathrm{mL}$ para animais com peso superior a $10 \mathrm{~kg}$. Este tratamento era repetido duas vezes ao dia durante todo o período de internação.

Foram anotadas as reações dos animais e a ocorrência de náusea ou vômito após a administração. A tolerância dos animais foi graduada como sendo ótima, quando o paciente demonstrava interesse em ingerir o produto; boa, quando aceitava com facilidade; regular, quando relutava em ingerir o produto; ruim ou péssima quando a ingestão era forçada e ocorria náusea e/ou vômito após a ingestão.

Também foram registrados a duração do período de internação, freqüência de vômito e diarréia, e o desfecho do quadro (óbito ou alta hospitalar) de todos os pacientes, dados usados na avaliação da evolução do quadro clínico.

\section{Fezes e soro}

De todos os animais foram colhidos, através de sonda retal e aspiração com seringa, $5 \mathrm{~mL}$ de fezes, tanto no momento da internação como na alta hospitalar. Nos mesmos momentos foram colhidos 3 $\mathrm{mL}$ de sangue sem anticoagulante para obtenção de soro. As amostras de fezes e soro foram identificadas e mantidas sob refrigeração até o momento do processamento.

\section{Titulação de partículas virais nas fezes pela técnica de hemaglutinação (HA)}

Para a identificação de partículas de parvovírus canino (CPV), aproximadamente $500 \mathrm{~mL}$ de fezes foram homogeneizadas vigorosamente e centrifugados à $12000 \mathrm{rpm}$ por dois minutos em microcentrifuga, o sobrenadante recolhido e o "pelete" resultante descartado. A técnica foi realizada em microplacas de poliestireno com 96 cavidades com fundo em U. Todas as cavidades foram preenchidas com $25 \mu \mathrm{L}$ de diluente do antígeno - tampão borato - BBS ( $\mathrm{NaCl} 1,5 \mathrm{M} ; \mathrm{H}_{3} \mathrm{BO}_{3} ; \mathrm{NaOH}$ $1,0 \mathrm{M} ; \mathrm{pH} 9,0)$. Na primeira cavidade de cada fileira foram adicionados $25 \mu \mathrm{L}$ do sobrenadante de cada amostra de fezes, homogeneizados e diluídos na base 2 até a $11^{\text {a }}$ cavidade, sendo desprezada a última diluição. A $12^{\text {a }}$ fileira foi utilizada como controle positivo do CPV canino e das hemácias. Na sequiência, em todas as cavidades foram adicionados $25 \mu \mathrm{L}$ de hemácias de suíno a $0,5 \%$. A placa era mantida em câmara úmida a $4^{\circ} \mathrm{C}$ durante 3 horas. Após esse período era observada a ocorrência ou não da hemaglutinação. Nas amostras em que não se observava o "end point" prosseguia-se com a diluição. Foram consideradas positivas as amostras com títulos iguais ou superiores a 512 (BURROWS; BATT; SHERDING, 1995).

\section{Titulação de anticorpos anti-CPV pela técnica de inibição da hemaglutinação (HI)}

Para verificar o título de anticorpos contra o CPV a técnica de $\mathrm{HI}$ foi realizada em placas de poliestireno com 96 cavidades com fundo em forma de U. Todas as cavidades foram preenchidas com $25 \mu \mathrm{L}$ de tampão borato - BBS (NACL 1,5 M; $\mathrm{H}_{3} \mathrm{BO}_{3} 0,5 \mathrm{M}$; $\mathrm{NaOH}$ 1,0 M; pH 9,0). Na primeira cavidade de cada fileira adicionava-se $25 \mu \mathrm{L}$ de cada amostra de soro, homogeneizava e prosseguia-se com a diluição seriada na base 2 até a $11^{\text {a }}$ cavidade sendo desprezado os $25 \mu \mathrm{L}$ restantes. A $12^{\mathrm{a}}$ fileira foi utilizada como controle positivo do vírus e da hemácia. Em seguida foram adicionados $25 \mu \mathrm{L}$ de amostra de vírus padrão com $8 \mathrm{U}$ em todas as cavidades, exceto no controle de hemácias. A placa foi incubada em estufa a $37{ }^{\circ} \mathrm{C}$ durante uma hora. Após este período aplicava-se $50 \mu \mathrm{L}$ de hemácias de suíno a $1 \%$ em todas as cavidades e incubava-se a placa em câmera úmida a $4{ }^{\circ} \mathrm{C}$ por 3 horas. Após este período, 
realizava-se leitura visual da ocorrência ou não da hemaglutinação. Nas amostras de soro em que não foi possível encontrar o "end point" prosseguia-se com as diluições. Os títulos obtidos foram anotados para posterior avaliação.

\section{Análise estatística}

A idade dos animais do G1 e do G2 e duração do período de internação entre os dois grupos foram comparados pelo teste de Mann-Whitney. A ocorrência de machos e fêmeas e a proporção de mortalidade entre os grupos foi avaliada pelo teste do Qui quadrado.

Os resultados das titulações, tanto de anticorpos anti-parvovírus como de vírus em amostras de fezes, as quais são expressas como fator de diluição (1:4, $1: 8,1: 16$, e assim sucessivamente) foram convertidas em escores, sendo o resultado negativo considerado 0 , a diluição menor, de 1:4 convertida em escore 1; a de 1:8 em escore 2; e assim sucessivamente até a diluição máxima de 1:2048, cujo escore era 10. Estes dados foram analisados por testes estatísticos não- paramétricos, sendo a titulação sérica de partículas virais nas fezes e de anticorpos anti-parvovírus no momento da internação e da alta foram comparados pelo Wilcoxon signed rank test, enquanto MannWhitney rank sun test foi empregado para a comparação entre os grupos (ZOLMAN, 1993).

\section{Resultados e Discussão}

Agrupados ao acaso, o grupo dos animais que receberam o tratamento padrão mais probiótico (G1) foi composto por filhotes de diferentes raças ou sem raça definida (SRD), 34 machos e 16 fêmeas, cuja idade variava de 45 dias a oito meses $(x=4,31 \pm$ 1,87). O grupo controle (G2) foi formado também por 50 filhotes, com dois a oito meses de idade $(\mathrm{x}=$ 4,36 $\pm 1,61$ ), 28 machos e 22 fêmeas (tabela 1), também de diferentes raças ou sem raça definida. Não houve diferença estatística significativa $(\mathrm{P}=$ $0,61)$ entre a idade dos animais dos dois grupos, assim como na ocorrência de machos e fêmeas $(\mathrm{P}=0,30)$ (tabela 1).

Tabela 1. Variação, média e desvio padrão, da idade (em meses), distribuição de gênero, variação da duração, média e desvio padrão do período de internação (em dias) e evolução do quadro clínico dos cães filhotes do G1 e do G2. Londrina, 2005.

\begin{tabular}{|c|c|c|c|c|c|c|}
\hline \multirow[t]{2}{*}{ Grupo } & \multirow[t]{2}{*}{ Variação de idade } & \multicolumn{2}{|c|}{ Gênero } & \multirow{2}{*}{$\begin{array}{c}\text { Variação do período } \\
\text { de internação }\end{array}$} & \multicolumn{2}{|c|}{ Evolução do quadro } \\
\hline & & machos & fêmeas & & alta & óbito \\
\hline \multirow[t]{2}{*}{ G1 } & $1,5-8$ & $34^{2}$ & $16^{2}$ & $1-15$ & $* 30^{4}$ & $* 18^{4}$ \\
\hline & $\mathrm{x}=4,31 \pm 1,87^{l}$ & & & $x=4,66 \pm 2,65^{3}$ & & \\
\hline \multirow[t]{2}{*}{$\mathrm{G} 2$} & $2-8$ & $28^{2}$ & $22^{2}$ & $1-10$ & $37^{4}$ & $13^{4}$ \\
\hline & $X=4,36 \pm 1,61^{l}$ & & & $x=4,46 \pm 2,68^{3}$ & & \\
\hline
\end{tabular}

Foram considerados positivos para parvovirose canina 31 animais do G1 e 30 do G2 que apresentaram títulos de HA iguais ou superiores a 1:520, não havendo diferença significativa $(\mathrm{P}=0,48)$ dentre os dois grupos quanto a ocorrência de parvovirose.
Também não foi observada diferença estatisticamente significativa na excreção viral dentre G1 e o G2, tanto nas amostras colhidas no momento do internamento $(\mathrm{P}=0,74)$ como no da alta hospitalar $(\mathrm{P}=0,29)$. Porém, a análise pareada da titulação de 
partículas virais nas amostras de fezes colhidas nos diferentes momentos revelou um fato importante. No G1, a titulação de vírus foi significativamente superior $(\mathrm{P}<0,001)$ nas amostras de fezes colhidas no momento da internação do que naquelas colhidas no momento da alta hospitalar, enquanto no G2 (grupo controle) não houve diferença estatisticamente significativa $(\mathrm{P}=0,078)$ entre os dois momentos (tabela 2). Este dado sugere que o uso de probiótico no tratamento de animais com enterite causada pelo $\mathrm{CPV}$, a semelhança do observado em crianças com diarréia causada pelo rotavírus, pode encurtar o período de excreção viral, ou diminuir a intensidade desta excreção (GUARINO et al., 1997; SHORNIKOVA et al., 1997; SIMAKACHORN et al., 2000; LEE et al., 2001; ROSENFELDT et al., 2002a; ROSENFELDT et al., 2002b).

Tabela 2. Freqüência de ocorrência de escores de título de parvovírus nas fezes dos animais do G1 e G2 no momento da internação e da alta hospitalar. Londrina, 2005.

\begin{tabular}{ccccc}
\hline \multirow{2}{*}{ Escore } & \multicolumn{3}{c}{ Títulos de parvovírus na fezes (HA) } \\
\cline { 2 - 5 } & \multicolumn{3}{c}{ G1 } & \multicolumn{3}{c}{ G2 } \\
\cline { 2 - 5 } & ${ }^{\boldsymbol{a}}$ Internação $^{\boldsymbol{l}}$ & ${ }^{\boldsymbol{a}}$ Alta $^{\mathbf{2}}$ & ${ }^{\boldsymbol{b}}$ Internação $^{\boldsymbol{l}}$ & ${ }^{\boldsymbol{b}}$ alta $^{\mathbf{2}}$ \\
\hline $\mathbf{0}$ & 25 & 18 & 28 & 16 \\
$\mathbf{1}$ & 0 & 0 & 0 & 2 \\
$\mathbf{2}$ & 1 & 4 & 2 & 0 \\
$\mathbf{3}$ & 3 & 0 & 1 & 0 \\
$\mathbf{4}$ & 2 & 1 & 0 & 0 \\
$\mathbf{5}$ & 2 & 1 & 5 & 5 \\
$\mathbf{6}$ & 1 & 2 & 2 & 2 \\
$\mathbf{7}$ & 2 & 2 & 1 & 1 \\
$\mathbf{8}$ & 2 & 1 & 2 & 4 \\
$\mathbf{9}$ & 3 & 0 & 2 & 1 \\
$\mathbf{1 0}$ & 4 & 2 & 4 & 3 \\
\hline
\end{tabular}

${ }^{a}$ Ocorrência de escores de títulos de partículas virais do G1 no momento da internação significativamente maior do que na alta hospitalar $(\mathrm{P}<0,001) ;{ }^{b}$ Sem diferença significativa $(\mathrm{P}=0,078) ;{ }^{1}$ Sem diferença significativa $(\mathrm{P}=$ $0,74) ;{ }^{2}$ Sem diferença significativa $(\mathrm{P}=0,29)$.

Os títulos de anticorpos anti-parvovírus foram aferidos usando-se a técnica de inibição da hemaglutinação (HI). A análise estatística da ocorrência de escores dos títulos de anticorpos demonstrou não haver diferença entre o $\mathrm{G} 1$ e o G2, tanto nas amostras de soro colhidas no momento da entrada $(\mathrm{P}=0,553)$, como no da alta hospitalar $(\mathrm{P}=$
0,844). Porém, a análise pareada das amostras colhidas no momento do internamento e da alta demonstrou aumento estatisticamente significativo $(\mathrm{P}<0,001)$ na concentração sérica de anticorpos durante o período de internamento, tanto no G1 como no G2 (tabela 3). Estas observações indicam que os grupos eram homogêneos em relação a esta variável, e que a administração do probiótico aos animais do G1 não induziu diferença na produção de anticorpos anti-parvovírus durante o período de internação em relação ao grupo controle. Sendo assim, o incremento na concentração sérica de anticorpos nos dois grupos provavelmente reflete uma resposta orgânica normal frente a infecção, visto que a soroconversão pode ocorrer ainda na fase aguda da doença (HOSKINS, 1998).

A evolução da doença foi avaliada pela observação da freqüência do vômito e diarréia, pela taxa de mortalidade e duração do período de internação. Os pacientes eram tidos como aptos a receberem alta quando não apresentavam vômito e diarréia a pelo menos doze horas, estavam alerta, demonstravam apetite e ingeriam água e alimento sem vômito posterior. O período de internamento dos animais do G1 variou de um a 15 dias ( $\mathrm{x}=4,66 \pm 2,65)$, enquanto nos do $\mathrm{G} 2$ variou de um a 10 dias $(\mathrm{x}=4,46 \pm 2,68)$, não havendo diferença estatisticamente significativa entre os dois grupos $(\mathrm{P}=0,70)$ (tabela 1$)$.

Uma das justificativas para o emprego de probióticos no tratamento de cães filhotes com GEH seria o efeito de proteção decorrente da capacidade de restabelecer o equilíbrio da microbiota intestinal residente (ISOLAURI et al., 1994), visto que, devido a quebra da barreira epitelial, a sepse e endotoxemia são contribuintes importantes para a mortalidade (HAGIWARA; MAMIZUKA; PAVAN, 1996; STEVEN, 1996). A hipótese de que a inclusão do probiótico no protocolo terapêutico poderia resultar em proteção e benefícios ao paciente não foi confirmada, pois não se observou diferença no curso da doença ou no período de internamento entre os animais tratados e não tratados. 
Tabela 3. freqüência de ocorrência de escores de título sérico de anticorpos dos animais do G1 e G2 no momento da internação e da alta hospitalar. Londrina, 2005.

\begin{tabular}{|c|c|c|c|c|}
\hline \multirow{3}{*}{ Escore } & \multicolumn{4}{|c|}{ Títulos de Ac séricos (HI) } \\
\hline & G1 & & G2 & \\
\hline & ${ }^{a}$ Internação ${ }^{l}$ & ${ }^{a}$ Alta $^{2}$ & ${ }^{b}$ Internação ${ }^{1}$ & ${ }^{b} \mathbf{A l t a}^{2}$ \\
\hline $\mathbf{0}$ & 7 & 4 & 9 & 6 \\
\hline 1 & 1 & 0 & 0 & 0 \\
\hline 2 & 4 & 2 & 2 & 2 \\
\hline 3 & 3 & 3 & 2 & 0 \\
\hline 4 & 3 & 1 & 3 & 0 \\
\hline 5 & 10 & 4 & 8 & 8 \\
\hline 6 & 3 & 3 & 5 & 8 \\
\hline 7 & 3 & 6 & 2 & 1 \\
\hline 8 & 0 & 2 & 3 & 4 \\
\hline 9 & 3 & 1 & 4 & 2 \\
\hline 10 & 7 & 4 & 7 & 3 \\
\hline
\end{tabular}

${ }^{a, b}$ Diferença dos escores de titulação de anticorpos significativamente menor no momento da internação do que na alta em ambos os grupos $(\mathrm{P}<0,001)$; ${ }^{\prime}$ Sem diferença significativa $(\mathrm{P}=0,55) ;{ }^{2}$ Sem diferença significativa $(\mathrm{P}=0,84)$.

Dentre os animais do G1, 20 vieram a óbito durante o período de internamento, porém, como dois deles foram eutanasiados por solicitação de seus proprietários, para efeito de análise estatística foram considerados 18 óbitos dentre 48 (37,50\%) animais neste grupo. No G2 ocorreram 13 (26\%) óbitos. O teste do Qui quadrado demonstrou que a diferença na taxa de mortalidade observada entre os dois grupos não era estatisticamente significativa $(\mathrm{P}=$ 0,49) (tabela 1). Apesar da falta de significância estatística, esta diferença chama a atenção, visto que morreram mais animais que receberam probiótico do que dentre os que não receberam. Deve-se ressaltar, porém, que a GEH em filhotes é uma síndrome clínica de origem multifatorial que pode ser decorrente de parasitismo intestinal (Ancylostoma sp., por exemplo), infecções bacterianas (Salmonella sp., Campylobacter sp.), virais (cinomose e notadamente a parvovirose), obstruções intestinais ou intussuscepção, e algumas destes processos podem ocorrer simultaneamente no filhote. Com relação a parvovirose, fatores como raça, idade, presença e intensidade de leucopenia, infecções concomitantes por outros vírus e parasitas (BRUNNER; SWANGO, 1995; BURROWS; BATT; SHERDING, 1995), são fatores que afetam a taxa de sobrevivência, ou pioram o prognóstico, e estes não foram investigados nem relacionados neste estudo. A imaturidade dos mecanismos de compensação e do sistema imunológico dos filhotes contribui para a instalação e agravamento de desidratação, desequilíbrio hídrico e eletrolítico, e desenvolvimento de infecções oportunistas ou translocação bacteriana, complicações que resultam no agravamento do quadro clínico e aumentam a chance de ocorrer sepse, endotoxemia e morte.

Os parâmetros clínicos utilizados para optar-se pela internação dos animais e a falta de condições para se conhecer todos os possíveis agentes etiológicos envolvidos na gênese do quadro clínico do pacientes, certamente não permitem que se afirme que todos os animais envolvidos na pesquisa se encontravam sob as mesmas condições metabólicas e tivessem a mesma chance de sobrevivência. Por isso, salvo se lactobacilos puderem penetrar através da mucosa lesada e causar sepse, não se pode relacionar o tratamento com probiótico a maior mortalidade dentre os animais tratados.

A apresentação do produto utilizado foi adequada e prática para o tratamento, além de ter boa palatabilidade, pois a maioria dos animais tolerou bem o produto utilizado. Dentre os que sobreviveram à doença, o padrão de aceitação variou de regular a ótimo em $95 \%$ das administrações, sendo que as avaliações regulares, em sua maioria, ocorreram na fase inicial do tratamento, quando havia maior ocorrência de vômito. Por outro lado, todos os animais que vieram a óbito demonstraram intolerância, com padrão de aceitação variando sempre de regular a péssimo, visto que demonstraram náusea, mímica do vômito e muitas vezes vomitaram logo após a ingestão. A intolerância ao produto provavelmente esta relacionada a maior gravidade do quadro, visto que estes animais vieram a óbito.

Neste estudo, envolvendo apenas filhotes de cão com gastrenterite hemorrágica, não pudemos estabelecer relação entre a administração de uma preparação comercial contendo Lactobacillus acidophillus e uma melhora na evolução da doença ou na abreviação do período de internação, nem 
efeito benéfico sobre a resposta humoral durante o curso da doença. Porém, aparentemente, esta suplementação influi positivamente na excreção fecal de vírus, o que é um fator positivo para a diminuição da contaminação ambiental e propagação da doença entre os animais susceptíveis.

\section{Referências}

BURROWS, C. F.; BATT, R. M.; SHERDING, R. G. Diseases of the small intestine. In: ETTINGER, S. J.; FELDMAN, E. C. Textbook of Veterinary Internal Medicine. 4 ed. Philadelphia: WB Saunders, 1995. v.2, Cap.104, p.11691232

CANDUCCI, F.; CREMONINI, F.; ARMUZZI, A.; DICARO, S.; GABRIELLI, M; SANTARELLI, L.; NISTA, E.; LUPASCU, A.; DE MARTINI, D.; GASBARRINI, A. Probiotics and Helicobacter pylori eradication. Digestive and Liver Diseases, Netherlands, v.34, n.9, Supl.2, p.8183, sep. 2002.

GARDINER, G. E.; HEINEMANN, C.; BAROJA, M. L.; BRUCE, A. W.; BEUERMAN, D., MADRENAS, J.; REID, G. Oral administration of the probiotic combination Lactobacillus rhamnosus GR-1 and L. fermentum RC-14 for human intestinal applications. International Dairy Journal, Barking, v.12, n.2-3, p.191-196, 2002.

GUARINO, A.; CANANI, R. B.; SPAGNUOLO, M. I.; ALBANO, F.; DIBENEDETTO, L. Oral bacterial therapy reduces the duration of symptoms and viral excretion in children with mild diarrhea. Journal of Pediatric Gastroenterology and Nutrition, Philadelphia, v.25, n.5, p.516-519, nov. 1997.

HAGIWARA, M. K.; MAMIZUKA, E. M.; PAVAN, M. F. B. Role of intestinal flora in acute hemorrhagic gastroenteritis (Parvovirus infection) of dogs. Brazilian Journal of Veterinary Research and Animal Sciences, São Paulo,v.33, n.2, p.107-109, 1996.

HOLZAPFEL, W. H.; SCHILLINGER, U. Introduction to pre- and probiotics. Food Research International, Barking, v.35, n.2-3, p.109-116, 2002.

HOSKINS, J.D.Canine viral enteritis. In: GREENE, C. E. Infectures diseases of the dog and cat. Philodelphia: W. B. Saunders, 1998. $2^{\mathrm{a}}$ ed. Cap. 45.

ISOLAURI, E.; KAILA, M.; MYKKANEN, H.; LING, H.; SALMINEN, S. Oral bacteriotherapy for viral gastroenteritis. Digestive Deseases and Sciences, New York, v.39, n.12, p.2595-2600, 1994.
JAHREIS, G.; VOGELSANG,H.; KIESSLING, G.; SHCBERT, R.; BUNTE, C.; HAMMES, W. P. Influence of probiotic sausage (Lactobacillus paracasei) on blood lipids and immunological parameters of healthy volunteers. Food Research International, Barking, v.35, n.2-3, p.133-138, 2002.

LEE, M. C.; LIN, L. H.; HUNG, K. L.; WU, H. Y. Oral bacterial therapy promotes recovery from acute diarrhea in children. Acta Pediatrica Taiwanica, Taiwan, v.42, n.5, p.301-305, 2001.

LIDEBECK, A.; NORD, C. E. Lactobacilli and the normal human anaerobic microflora. Clinical Infectious Diseases, Chicago, v.16, supl.4, p.181-187, 1993.

PESSI, T.; SÜTAS, Y.; MARTTINEN, A.; ISOLAURI, E. Probiotics reinforce mucosal degradation of antigens in rats: implications for therapeutic use of probiotics. Journal of Nutrition, Philadelphia, v.128, n.12, p.2313-2318, dec. 1998.

ROSENFELDT, V.; MICHAELSEN, K. F.; JAKOBSEN, M., LARSEN, C. N.; MOLLER, P. L.; PEDERSEN, P. ;TVEDE, M; WEYREHTER, H.; VALERIUS, N.H.; PAERREGAARD, A. Effect of probiotic Lactobacillus strains in young children hospitalized with acute diarrhea. The Pediatric Infectious Disease Journal, Baltimore, v.21, n.5, p.411416, may 2002 a.

ROSENFELDT, V.; MICHAELSEN, K.F.; JAKOBSEN, M., LARSEN, C.N.; MOLLER, P.L.; TVEDE, M; WEYREHTER, H.; VALERIUS, N.H.; PAERREGAARD, A. Effect of probiotic Lactobacillus strains in a cohort of nonhospitalized children attending day-care centers. The Pediatric Infectious Disease Journal, Baltimore, v.21, n.5, p.417-419, may 2002 b.

SHORNIKOVA, A.V.; CASAS, I. A.; MYKKANEN, H.; SALO, E.; VESIKARI, T. . Bacteriotherapy with Lactobacillus reuteri in rotavirus gastroenteritis. The Pediatric Infectious Disease Journal, Baltimore, v.16, n.12, p.1103-1107, 1997.

SIMAKACHORN, N.; PICHAIPAT, V.; RITHIPORNPAISARN, P.; KONGKAEW， C.; TONGPRADIT, P.; VARAVITHYA, W. Clinical evaluation of the addition of lyophilized, heat-killed Lactobacillus acidophilus LB to oral rehydration therapy in the treatment of acute diarrhea in children. Journal of Pediatric Gastroenterology and Nutrition, Philadelphia, v.30, n.1, p.68-72, 2000.

STEVEN, W.; D. Acute Medical Diseases of the Small Intestine. In: TAMS, T. Handbook of Small Animal Gastroenterology. Philadelphia: W.B. Saunders, 1996. Cap.6. 
SZAJEWSKA, H.; MRUKOWICZ, J. Z. Probiotics in the treatment and prevention of acute infectious diarrhea in infants and children: a systematic review of published randomized, double-blind, placebo-controlled trials. Journal of Pediatric Gastroenterology and Nutrition, Philadelphia, v.33, Supl.2, p.S17-S25, 2001.
VAN NIEL, C. W.; FEUDTNER, C.; GARRISON, M. M.; CHRISTAKIS, D. A. Lactobacillus therapy for acute infectious diarrhea in children: meta analysis. Pediatrics, Elk Grove Village, v.109, n.4, p.678-684, 2002.

ZOLMAN, J.F. Biostatistics: experimental design and statistical inference. New York: Oxford University Press, 1993. p.343. 
